\title{
BIOTECNOLOGÍA, ÉTICA E IMPLICACIONES JURÍDICAS ANTE LOS CIBORG-ATLETAS
}

\section{BIOTECHNOLOGY, ETHICS AND LAW IMPLICATIONS IN FRONT OF CYBORG-ATHLETES}

\author{
Dra. Silvia Irene VERDUGO GUZMÁN.
}

RESUMEN: Frente al deporte actual es clave considerar el profesionalismo con que se practica además del valor comercial presente hace unos años, que han hecho cambiar muchas disciplinas logrando eventos deportivos increíbles cada vez con más intervinientes. Es evidente que innumerables atletas participan utilizando tecnología o sistemas cada vez más avanzados. La cuestión está en que parece ser que las propias sociedades globalizadas lo aceptan en aras de obtener competiciones que sobrepasen los límites del ser humano, incluso por medio de los llamados ciborg-atletas ${ }^{1}$. De esta manera, quedan atrás problemas como el dopaje genético porque nos encontramos frente a nuevos dilemas éticos, jurídicos y biotecnológicos en el deporte.

ABSTRACT: In the actual sport world are important different facts around professionalism and comercial signs, because they Will be change a lot of disciplines for incredible sports events. Some athletes training using technology or advanced systems, but also the globalized society accept this for competitions outside of limits of body human, too this is possible with cyborg-athletes. For that reason problems about gene doping and others, are behind, because we are in front of paradigm ethics, new laws and biotechnology in sports.

Palabras Clave: Derecho, deporte, Biotecnología, ciborg-atletas, mejoramiento humano, juego limpio.

KEY WORDS: Law, Sport, Biotecnology, ciborg-athletes, enhancement, fair play.

\footnotetext{
${ }^{1}$ «El acrónimo ciborg procede del inglés cyber (cibernético) y organism (organismo), esto es, organismo cibernético. Los ciborg son en este sentido organismos compuestos de elementos orgánicos y dispositivos mecánicos, electrónicos o robóticos, los cuales sirven principalmente para mejorar las capacidades de la parte orgánica mediante el uso de la tecnología», en J. PÉREZ TRIVIÑO, «Implantes y prótesis: de la terapia al ciborgdeportista», en A. MiLlán GARRIDO / L. CERVANTES LiÑán (dirs.), Anuario Iberoamericano de Derecho Deportivo, edit. U. Inca Garcilaso de la Vega, núm. 3, 2015, Lima, p. 36.
} 


\section{EL DEPORTE EN LAS SOCIEDADES GLOBALIZADAS}

Los antecedentes sobre los orígenes de diversas actividades deportivas en distintos sitios del planeta son más que evidentes. Con el tiempo, se fue gestando una regulación no sólo en cada disciplina, sino que también a nivel internacional era necesario uniformar la temática, especialmente por su notable repercusión a nivel mundial. Por ello, se intensifica cada vez más un marco normativo serio y efectivo para lograr una expansión oportuna. En este sentido, destaca por ejemplo que en la cúspide normativa del deporte se encuentre la Carta Olímpica, pues ésta expresa que es misión y papel del Comité Olímpico Internacional promover el fomento de valores fundamentales en el olimpismo, como lo es la ética deportiva y buscando la prevalencia del juego limpio ${ }^{2}$.

En efecto, la diversa normativa jurídica internacional que regula el deporte se pronuncia también en torno a diversas temáticas; la perfección de sus reglas, la intensificación de la lucha contra el dopaje deportivo y la corrupción, el desarrollo de competiciones accesibles a cualquier persona (por ejemplo, las cada vez más masivas carreras de maratón), entre otros temas. Las políticas básicas de los intervinientes se refieren a la protección de valores como son la ética deportiva, una participación en igualdad de condiciones, la conservación de la salud e integridad física y psíquica de los atletas ante problemas como el dopaje ${ }^{3}$.

Por lo anterior, destaca el constante avance y modificación de todo aquello que abarca el deporte, esto es, desde las reglas de una disciplina hasta los organismos o

\footnotetext{
${ }^{2}$ Article 2. Mission and Role of the International Olympic Committee, Olympic Charter, Lausanne / Switzerland, 15.IX.2017. Accesible en: https://stillmed.olympic.org/media/Docu-ment\%20Library/OlympicOrg/General/EN-OlympicCharter.pdf. Consultado el 1.IX.2018.

${ }^{3}$ Entre los Fundamentos del Código Mundial Antidopaje se establece, «(l)os programas antidopaje pretenden proteger lo intrínsecamente valioso del deporte. Este valor intrínseco se denomina a menudo «espíritu deportivo», es la esencia misma del olimpismo, la búsqueda de la excelencia humana a través de la perfección de los talentos naturales de la persona, es el juego limpio. El espíritu deportivo es la celebración del espíritu humano, el cuerpo y la mente, y se refleja en los valores que encontramos en el deporte, (...)», en Código Mundial Antidopaje (trad. al español de S. Verdugo Guzmán), Editorial Flores, México, D.F., 2016, p. 45.
} 
federaciones internacionales que se encuentran supervisando que todo se desarrolle dentro de los parámetros y directrices otorgados por sus intervinientes. Así sucede cuando un país quiere postular a la organización de algún mundial en cierto deporte o de los Juegos Olímpicos, debiendo cumplir estrictos parámetros y normas que le permitan la cada vez más ansiada por muchos países- adjudicación de un torneo internacional ${ }^{4}$.

Gracias a las nuevas tendencias sociales y los modernos métodos de comunicación existentes en casi todo el planeta, nos encontramos en un mundo globalizado que afecta a la sociedad en su conjunto y respecto a lo cual el deporte no puede mantenerse al margen, al contrario, el llamado a éste es que debe estar atento a los cambios que se presenten para una oportuna adaptación en aras de seguir cumpliendo con los objetivos descritos en todo el marco normativo que lo regula. Así por ejemplo, hasta no hace muchos años se podía hacer trampa jugando al ajedrez mediante "formas convencionales", sin embargo, actualmente incluso en su normativa se prohíbe el uso de teléfonos móviles en una competición, ante la posibilidad de que un jugador pueda detectar y obtener las posibles jugadas para así conseguir la victoria del jugador.

En su momento fue problemático descubrir cómo mejorar la vida de las personas que sufrían dolencias poco comunes o sin una solución aparente, pero ello fue avanzando con el transcurso del tiempo y actualmente la cuestión llamativa está en detectar si una persona tiene incorporado en su organismo algún implante que no le causa perjuicios a su salud. En este sentido, siguiendo a QUIGLEY y AYIHONGBE, los desafíos actuales de las ciencias son, "la transgresión de los límites corporales; la integración de las tecnologías con las personas; la vinculación de lo biológico con materiales sintéticos; y, la naturaleza de las tecnologías como bienes integrados en torno al ser humano"5.

Sin embargo, el problema que se presenta, a efectos de este trabajo, es respecto a los deportistas que se encuentran en búsqueda de la perfección y gloria a un nivel competitivo superando los límites y capacidades del ser humano común. Cabe precisar

\footnotetext{
${ }^{4}$ S. VERDUGO GUZMÁN, «Derecho y deporte profesional: globalización y ciborgdeportistas», en Revista Actualidad Penal, editorial Instituto Pacífico, núm. 42, Lima, 2017, pp. 326 y ss.

${ }^{5}$ Quigley, Muireann / AYIHONGBE, Semande, «Everyday cyborgs: on integrated persons and integrated goods», in Medical Law Review, Oxford University Press, 22.II.2018, pp. 1-33, esp. p. 27.
} 
que está permitido si existen justificaciones terapéuticas, pero en otras ocasiones y cuando no son necesarias o justificadas, hace falta demarcar los límites jurídicos para que éticamente sea posible participar en igualdad de condiciones entre todos los atletas en aras de ganar la anhelada medalla o suculento premio en una competición.

\section{FUNCIÓN SOCIAL DEL DEPORTE}

La Comisión Europea se preocupó de regular la temática deportiva hace algunos años atrás mediante su documento de consulta, el Modelo de Deporte Europeo, que describe la estructuración de los diversos entes deportivos que se encuentran organizados por medio de federaciones europeas e internacionales vinculadas jerárquicamente ${ }^{6}$. Pero también ese Modelo de Deporte es importante (y atractivo a nivel social), porque reconoce un compromiso con la identidad nacional de quienes practican actividades deportivas. Esto significa que su intención es otorgar una estabilidad social y simbolizar la inmensa diversidad cultural existente ${ }^{7}$, especialmente gracias a las nuevas tendencias y modernas tecnologías que se utilizan en el deporte.

En efecto, el deporte ha presentado un importante crecimiento a nivel económico en Europa principalmente a partir de 1980, frente a lo cual la propia Unión Europea busca constantemente herramientas que permitan manejar lo más preciso posible el marco deportivo. En esta materia, el Libro Blanco sobre el Deporte, reconoce la importancia e impacto macroeconómico que este fenómeno genera, pues se trata de un sector cada vez más globalizado y dinámico ${ }^{8}$. Así las cosas, el deporte amateur se ve en la necesidad de adaptarse a la nueva realidad en que se encuentra inmerso

\footnotetext{
${ }^{6}$ Sobre la organización y estructura piramidal del deporte en Europa, Modelo de Deporte Europeo, Documento de consulta de la DG X (1999/C 374/14), Comisión Europea, Bruselas, 15.IX.1999. Accesible en la página web siguiente: http://www.eurored-deporte.net/gestor/documentos/modelo\%20del-\%20deporte\%20europeo.pdf. Consultado el 1.III.2018.

${ }^{7}$ Modelo de Deporte Europeo, Documento de consulta de la DG X (1999/C 374/14), cit.

${ }^{8}$ Libro Blanco sobre el Deporte, Comisión de las Comunidades Europeas, Bruselas, 11.VII.2007, p. 11. Accesible en: http://www.planamasd.es/sites/default/files/recursos/libro-blanco-sobre-el-depor-te-de-laue.pdf. Consultado el 1.IX.2018.
} 
BIOTECNOLOGÍA, ÉTICA E IMPLICACIONES JURÍDICAS ANTE LOS CIBORG-ATLETAS, Silvia Irene VERDUGO GUZMÁN (CEU Andalucía). sverdugo@ ceuandalucia.es Recibido: 18/10/2018. Aceptado: 16/05/2019 DOI: http://dx.doi.org/10.12795/IETSCIENTIA.2019.i01.05

reconfigurando sus organizaciones para lograr un punto de equilibrio entre su rol social y la creciente importancia económica que intenta obtener con el transcurso del tiempo 9 .

La profesionalización y seriedad con que se regulan normativamente muchos deportes, son producto de los cada vez más numerosos los eventos que se realizan a nivel mundial, mejorando entonces las oportunidades comerciales y expectativas económicas de bastantes interesados, tales como cadenas de televisión, empresas, marcas o auspiciadores, agentes de deportistas, entre otros, haciendo que además sea un mercado muy atractivo para quienes de algún modo se sienten involucrados con esa realidad. En este sentido, cada año son miles -por no decir millones- las ventas de camisetas de diversos equipos de fútbol que demandan los fanáticos según sea el jugador de moda o destacado de la temporada. Ni para qué decir cuando se acerca un mundial de fútbol ${ }^{10}$.

Bajo el mismo orden de ideas, es importante poner de manifiesto además que la materia del régimen jurídico aplicable a las cuestiones derivadas del control económico que están imponiendo con gran rigor las ligas profesionales es un claro ejemplo de esa intervención descrita, como en el caso de España, dentro del marco normativo económico y especialmente financiero, que están provocando la aplicación de mecanismos jurídicos y una implementación práctica cada vez más eficiente en los años recientes $^{11}$. Todo esto no es más que un claro ejemplo de la preocupación por parte de los entes que participan del fenómeno deportivo y quizás también producto de la supervisión de los organismos superiores a nivel internacional.

\section{DOPAJE, TECNOLOGÍA Y AFECTACIÓN A LA ECONOMÍA}

\footnotetext{
9 A. Guerrero Olea / R. Barba SÁnchez, «El modelo privado del Deporte en Europa: el deporte organizado convencionalmente», en A. Palomar Olmeda, El modelo europeo del deporte, editorial Bosch, Barcelona, 2002, p. 157.

${ }^{10}$ S. VERDUGO GUZMÁN, «Derecho y deporte profesional: globalización y ciborgdeportistas», cit., p. 330.

${ }^{11}$ M. GARCÍA CABA, «La publificación del régimen sancionador aplicable al control económico del fútbol profesional: una visión sucinta de la reciente doctrina del Tribunal Administrativo del Deporte en la materia», en A. Millán Garrido (dir.), Cuestiones actuales de derecho del deporte, editorial Reus, Madrid, 2015, pp.144 y ss.
} 
Se ha manifestado el notable crecimiento del deporte a nivel profesional. El ciclismo es uno de los deportes más practicados en el mundo -dejando de lado al fútbol, pero las expectativas de los seguidores fueron cayendo con el tiempo cuando se comenzó a hablar del dopaje tecnológico -aunque técnicamente se considera más correcto referirse a fraude tecnológico-, al detectarse que insertas en las bicicletas se encontraban pequeños motores o impulsores que ayudaban a obtener ventajas competitivas a los ciclistas con respecto a sus pares. Sin embargo, actualmente existen diversos mecanismos que intentan detectar ese fraude pasando las bicicletas por un escáner en la competición.

Lo anterior además es una nueva muestra de que sigue siendo una realidad lamentable que vinculado al deporte profesional se encuentre el problema del dopaje, básicamente porque el deporte se ha visto expuesto a un exceso de la intervención comercial con enormes repercusiones económicas y financieras ${ }^{12}$. Esto afecta directamente a los deportistas, que son los 'actores principales' de cada evento, pero que debido a la continua realización de competiciones -casi semanalmente- existe una inevitable sobrecarga deportiva especialmente de quienes se desempeñan a un alto nivel, que los obliga a recurrir a todo tipo de fármacos o métodos para lograr una rápida recuperación en aras de estar lo mejor posible para la próxima actividad que será televisada ${ }^{13}$. Así por ejemplo, deportistas intentan mitigar estos problemas a través de la crioterapia, esto es, por medio de reacciones químicas en el cuerpo humano debido a la aplicación de frío extremo (nitrógeno a temperaturas muy bajas, de aproximadamente $200^{\circ}$ Celsius), para que se produzca una mejor circulación sanguínea, la expedita recuperación muscular o una eliminación de sustancias perjudiciales para la salud; técnica legítima y utilizada por futbolistas como Cristiano Ronaldo, a modo de ejemplo ${ }^{14}$.

\footnotetext{
${ }^{12}$ S. VERdugo GuZMÁn, «Derecho y deporte profesional: globalización y ciborgdeportistas», cit., pp. 330 y ss.

${ }^{13}$ En efecto, el deporte profesional es uno de los principales sectores económicos, siendo entonces la razón del por qué los deportistas se dopan, y es para estar a las alturas de las exigencias que imponen rendimientos que ya no son excepcionales sino que desorbitados, en G. REAL FERRER, «Dopaje: el debate que viene», en G. Real FerRer (dir.), Justicia Deportiva, Editorial Aranzadi, Pamplona, 1999, p. 24.

${ }^{14}$ S. VERDUGO GUZMÁN, «Derecho y deporte profesional: globalización y ciborgdeportistas», cit., p. 333.
} 
Pero también los productos publicitarios (merchandising), como vestuario, insignias, videojuegos y un sinnúmero de elementos que mantienen estable a los agentes económicos, se ven afectados cuando se desenmascara un dopaje pues conlleva una gran pérdida de ganancias y credibilidad incluso a los auspiciadores de un deportista. Un claro ejemplo fue el caso de Lance Armstrong, que una vez confesó haber competido en ciclismo bajo un sofisticado sistema de dopaje probablemente desde el año 1993, trajo reacciones judiciales de sus diversos ex auspiciadores por las pérdidas millonarias que les produjo la noticia, afectándose directamente al sistema económico ${ }^{15}$.

De esta manera, está presente la necesidad de encontrar una intervención que justifique la protección del deporte cuando es atacado por el dopaje y que inevitablemente repercute en la economía ${ }^{16}$. En otros términos, si se considera la influencia que el tema económico ha logrado en el deporte estas últimas décadas, guarda una lógica muy necesaria la correcta protección de las competiciones justas y leales, y ello se justifica porque en efecto atentan contra la libre competencia al igual que ocurre en una economía de libre mercado ${ }^{17}$.

\section{BIOTECNOLOGÍA Y MEJORAS DEL RENDIMIENTO DEPORTIVO. EL DOPAJE GENÉTICO}

\footnotetext{
${ }^{15}$ Al mismo ciclista le significó a nivel deportivo el despojo de diversos premios e inhabilitación de por vida para competir. A nivel judicial está involucrado por estafa a varios de sus ex auspiciadores. Así, el Servicio Postal de los Estados Unidos (US Postal), busca el reparo de los daños causados por haber competido dopado durante años, en «Lance Amstrong afrontará un juicio millonario el 6 de noviembre en EEUU» (26.II.2017). Accesible en Portal de Derecho Deportivo: https://iusport.com/not/31712/lancearmstrong-afrontara-un-juicio-millonario-el-6-de-novi-embre-en-eeuu-. Consultado el día 1.IX.2018.

${ }^{16}$ Manifiesta Ríos CORBACHO su preocupación entre las relaciones del Derecho y el deporte, es decir, «(...) la influencia de los fenómenos sociales y culturales sobre las instituciones y, por consiguiente, sobre el Derecho; el fenómeno de la profesionalización en el deporte, la exagerada comercialización de la actividad deportiva, la proliferación de las grandes competiciones internacionales (europeas, latinoamericanas, intercontinentales y mundiales), el aumento de sujetos que se dedican a la actividad deportiva y el propio fomento del deporte por la Administración que van a instaurar relaciones legales diversas y que, como no puede ser de otra manera, deben ser reguladas y examinadas», en J. Ríos CORBACHO, Violencia, deporte y Derecho penal, Editorial Reus S.A., Madrid, 2014, p. 60.

${ }^{17} \mathrm{Y}$ en este sentido se vería justificada la intervención del Derecho penal, en C. Roxin, «Derecho penal y doping», en L. Morillas Cueva (dir.), Cuadernos de Política Criminal I, $2^{a}$ época, núm. 97, Editorial Centro de Estudios Superiores de Especialidades Jurídicas, Madrid, 2009, pp. 15 y ss.
} 
En toda sociedad globalizada se toleran ciertos riesgos que son inevitables por las condiciones y calidad de vida en que nos encontramos. Aquellos provenientes de los modernos avances tecnológicos han llevado a intervenciones médicas y al crecimiento de la biomedicina cada vez con más fuerza, otorgando día a día información sobre la mejora de enfermedades que hasta hace no muchos años era imposible si quiera diagnosticar o $\operatorname{tratar}^{18}$. Pero los tiempos han cambiado. Ya en las últimas décadas ha quedado de manifiesto la existencia de personas que mezclan la realidad con la tecnología en aras de lograr avances sin límite alguno, esto es, sobrepasando los límites sociales, éticos, normativos e incluso de las ciencias exactas ${ }^{19}$.

Lo anterior se relaciona con la manipulación de genes, es decir, actividades que en algunos casos se realizan fuera de los límites permitidos por la sociedad, pero que en otros han servido para regenerar células del cuerpo humano y mejorar la salud a cientos de enfermos. Sin embargo, el problema se presenta cuando esas actividades se practican con fines ilícitos, y el deporte no está ajeno a esto. Los avances científicos y médicos han llegado incluso a desarrollar tratamientos e intervenciones que sirven para mejorar el rendimiento físico y las capacidades del ser humano, donde uno de los grandes dilemas se encuentra en torno al dopaje genético, muy difícil de detectarlo especialmente con los métodos actuales ${ }^{20}$. En base a esto, la introducción o

\footnotetext{
${ }^{18}$ Siguiendo en este punto a PÉREZ Triviño, «(...), para fines cosméticos se permite la cirugía, el botox, la modificación corporal (piercing) o los supresores del apetito. En el ámbito de la música, es perfectamente posible tomar propranol para evitar los temblores que pueden afectar a un músico antes de un concierto. A un nivel más común, hay diferentes tipos de sustancias mejoradoras de nuestras capacidades cognitivas o para modificar el estado de ánimo: alcohol, nicotina, ritalin, modafenil, cafeína, prozac. Incluso existen sustancias que se adquieren en las farmacias para mejorar el rendimiento sexual, como la famosa viagra», en J. PÉREZ TRIVIÑO, «Implantes y prótesis: de la terapia al ciborgdeportista», cit., pp. 33 y 34.

${ }^{19}$ Así, PÉREZ Triviño expone, «(...), estamos experimentando cambios más profundos en la relación entre los seres humanos y la tecnología: la genética, la robótica, la cibernética, la nanotecnología y la biomedicina están planteando la posibilidad de que en el futuro los seres humanos puedan modificarse genéticamente, puedan clonarse, crearse seres híbridos o interactuar con ordenadores y otros componentes impuestos por la naturaleza y puedan experimentar cualquier cambio físico dirigido a aumentar sus capacidades fisiológicas y mentales», en J. PÉREZ TriviÑo, «Implantes y prótesis: de la terapia al ciborgdeportista», cit., p. 34.

${ }^{20}$ Hasta hace unos pocos años el fenómeno del dopaje genético aun dificulta su tratamiento debido a lo novedoso del mismo o también por encontrarse en una fase experimental de desarrollo. Por eso es importante delimitarlo para lograr su comprensión por parte de la Sociedad, en E. ATIENZA MACíAS, «Implicaciones ético-jurídicas de las intervenciones de mejora en el ámbito deportivo. Especial consideración del llamado 'dopaje genético'», en Carlos M. Romeo CASABOna (dir.), Revista de
} 
modificación de la actividad de las células presentes en una parte específica del cuerpo humano con la finalidad de producir ventajas adicionales al deportista, entendido como la actividad de transferir ADN, o el uso de células normales o genéticamente modificadas, es aquello que se produce por medio del denominado dopaje genético ${ }^{21}$.

A grandes rasgos, se puede señalar que el objetivo de estas técnicas es modificar las funciones a nivel genético de las células en el organismo humano, por ejemplo, para lograr una mayor alteración del tamaño de la musculatura, la estatura, de la rapidez en la curación de lesiones, del aumento del flujo sanguíneo, así como también la búsqueda de una mayor capacidad para la producción de energía; en resumen, obtener en el ser humano capacidades que hasta hace unos años ni siquiera eran imaginables ${ }^{22}$.

\section{LOS CIBORG-ATLETAS. IMPLICACIONES ÉTICAS Y JURÍDICAS}

La realidad en que nos encontramos no deja de sorprender. Día a día son dados a conocer nuevos avances tecnológicos en muchas esferas de la vida de las personas que en algunos casos buscan obtener una mejor calidad de vida, así como también comodidades o beneficios de diversa índole. Pero conforme las referencias de QUIGLEY y AYIHONGBE, el gran problema actual -a nivel del ser humano- es determinar cuándo la legislación considera que "algo" es una persona (sujeto) o una cosa (objeto). Por este motivo es importante una clara delimitación normativa, pues la clave está en que si existe una línea que permite distinguir entre persona y cosa, se podrá dar un enfoque acertado a la solución del problema que pueda presentarse (por ejemplo, en relación a la utilización de productos sanitarios defectuosos o en torno a los derechos de propiedad

Derecho y Genoma Humano. Cátedra Interuniversitaria Diputación Foral de Bizkaia de Derecho y Genoma Humano, U. de Deusto y U. del País Vasco UPV/EHU, Bilbao, 2014, p. 269.

${ }^{21}$ M3. Dopaje genético. Lo siguiente, con el potencial de mejorar el rendimiento, está prohibido: 1- La transferencia de polímeros de ácidos nucleicos o análogos de ácidos nucleicos; 2- El uso de células normales o genéticamente modificadas, en Métodos prohibidos. Lista de Sustancias y Métodos Prohibidos de la AMA. Estándar Internacional, 2018. Accesible en: https://wada-mainprod.s3.amazonaws.com/resources/files/wada-2018-prohibited-list-esp.pdf. Consultado el 1.IX.2018.

${ }^{22}$ S. VERDUGO GUZMÁN, «Imputación objetiva y riesgo permitido en intervenciones genéticas. El dopaje genético», en I. Jiménez Soto (dir.), Los Retos del deporte profesional y profesionalizado en la sociedad actual, editorial Reus, Madrid, 2016, pp. 450 y ss. 
IUS ET SCIENTIA (ISSN: 2444-8478) 2019, Vol.5, n 1, pp. 112-127

BIOTECNOLOGÍA, ÉTICA E IMPLICACIONES JURÍDICAS ANTE LOS CIBORG-ATLETAS, Silvia Irene VERDUGO GUZMÁN (CEU Andalucía). sverdugo@ ceuandalucia.es Recibido: 18/10/2018. Aceptado: 16/05/2019 DOI: http://dx.doi.org/10.12795/IETSCIENTIA.2019.i01.05

intelectual) ${ }^{23}$. En consecuencia, esa separación fronteriza será la que permita relacionar una serie de desafíos cotidianos con la realidad de los ciborgs ${ }^{24}$, como participantes de un deporte en igualdad de condiciones.

La regulación jurídica de esta materia se encuentra gestada especialmente en la Directiva 90/385/ECC (derogada recientemente por el Reglamento UE 2017/745, sobre productos sanitarios; también relacionada al Reglamento UE 2017/746, sobre los productos sanitarios para diagnósticos in vitro). Básicamente se refería a los implantables activos, y señalaba que estos engloban a instrumentos, dispositivos, equipos, programas informáticos, material u otro artículo, cuya finalidad está vinculada con la salud y mejoría de seres humanos ${ }^{25}$.

Pero también la tecnología tiene cada vez mayor cabida en el deporte y no sólo en aquellas disciplinas en que se utiliza algún tipo de vehículo, como en el ciclismo o el automovilismo, sino que también los avances tecnológicos ya afectan directamente al ser humano mediante mejoras en los materiales que se utilizan para practicar un deporte, como son zapatillas, jabalinas, palos de hockey o bicicletas ${ }^{26}$, y es aquí donde los agentes económicos están apareciendo cada vez con más frecuencia e invirtiendo grandes sumas de dinero en la creación de implementos o todo lo que tenga que ver con un deporte, como en la adjudicación de los derechos audiovisuales de alguna competición o de algún torneo importante. Sucede cada año con el Super Bowl, competición de fútbol americano cuya final es seguida cada vez por más personas en los Estados Unidos, y que en el año 2017 fue vista por 111,3 millones de espectadores a

\footnotetext{
${ }^{23}$ Quigley, Muireann / AYIHONGBE, Semande, «Everyday cyborgs: on integrated persons and integrated goods», cit., p. 27.

${ }^{24}$ QuigLEY, Muireann / AYIHONGBE, Semande, «Everyday cyborgs: on integrated persons and integrated goods», cit., p. 27-28.

${ }^{25}$ Así, producto sanitario es "cualquier instrumento, dispositivo, equipo, programa informático, material u otro artículo, utilizado solo o en combinación, junto con cualquier accesorio, incluidos los programas informáticos destinados por su fabricante a finalidades específicas de diagnóstico y/o terapia y que intervengan en su buen funcionamiento, destinado por el fabricante a ser utilizado en seres humanos con fines de: diagnóstico, prevención, control, tratamiento o alivio de una enfermedad; diagnóstico, control, tratamiento, alivio o compensación de una lesión o de una deficiencia, (...)”, Directiva 90/385/ECC, de 20.VI.1990, relativa a la aproximación de las legislaciones de los Estados miembros sobre los productos sanitarios implantables activos. Accesible en: http://eur-lex.europa.eu/LexUriServ/LexUriServ.do?uri=CONSLEG:1990L0385:-20071011:es:PDF Consultado el día 1.III.2018.

${ }^{26}$ J. L. PÉREZ TRIVIÑo, «Deportistas tecnológicamente modificados y los desafíos al deporte», en Revista de Bioética y Derecho, núm. 24, Universidad de Barcelona, Barcelona, enero 2012, p. 6.
} 
IUS ET SCIENTIA (ISSN: 2444-8478) 2019, Vol.5, nº 1, pp. 112-127

BIOTECNOLOGÍA, ÉTICA E IMPLICACIONES JURÍDICAS ANTE LOS CIBORG-ATLETAS,

Silvia Irene VERDUGO GUZMÁN (CEU Andalucía). sverdugo@ ceuandalucia.es

Recibido: 18/10/2018. Aceptado: 16/05/2019 DOI: http://dx.doi.org/10.12795/IETSCIENTIA.2019.i01.05

través de la cadena FOX Sports, quien obtuvo los derechos de transmisión, en el partido entre los Patriots de Nueva Inglaterra y los Falcons de Atlanta (ganando los primeros en la prórroga por 34-28) ${ }^{27}$.

Sin embargo, aunque la tecnología puede ser utilizada con distintos fines, el problema se presenta respecto al límite de la legitimidad y la prohibición en su uso con efectos mejoradores. Esto significa que como quiera que sea practicado el deporte, a estas alturas es preciso sostener que se encuentra influido y beneficiado por la tecnología, que es impulsada por los agentes económicos que además hacen publicidad con sus invenciones accesibles a cualquier persona y obteniendo lógicamente grandes beneficios $^{28}$.

Son cuestionables los avances tecnológicos usados en el deporte porque estarían afectando directamente al ser humano -deportista-. En este sentido, la polémica actual se refiere a la aceptación -o no- de ciborg-deportistas en actividades deportivas, básicamente porque los implantes mecánicos, electrónicos o robóticos, en principio tuvieron un objetivo terapéutico y restaurativo de las capacidades en quienes sufrían de ciertas limitaciones físicas o discapacidades. Con el transcurso del tiempo la cuestión ha cambiado pues ya hay casos de personas que ayudadas por la tecnología se han desempeñado también en el deporte ${ }^{29}$. El claro y cuestionable ejemplo de ciborgdeportista es Óscar Pistorius, atleta paralímpico sudafricano que utilizando prótesis transtibiales de fibra de carbono ha podido participar en diversas competiciones deportivas, donde el gran debate se produjo cuando pudo competir en los Juegos Olímpicos de Beiging el 2008 junto a los atletas que no tenían limitaciones físicas.

\footnotetext{
${ }^{27}$ Cabe destacar que los anuncios de televisión suelen costar entre 5 y 5,5 millones de dólares, mientras que las compañías se gastan una media de 400 millones en publicidad. Noticia publicada en Iusport, «La victoria épica de Patriots en el Super Bowl fue vista por 111,3 millones de espectadores» (7.II.2017). Accesible en Portal de Derecho Deportivo: https://iusport.com/not/30570/la-victoria-epica-de-patriots-enel-super-bowl-fue-vista-por-111-3-millones-de-espectadores.

${ }^{28}$ S. VERDUGO GUZMÁN, «Derecho y deporte profesional: globalización y ciborgdeportistas», cit., pp. 335 y ss.

${ }^{29}$ Lo ejemplifica J. PÉREZ TRIVIÑo, «(...), con la operación de Tommy John, nombre mediático con el que se conoce la reconstrucción del ligamento colateral medial del codo. Fue en 1974, cuando el doctor Frank Jobe llevó a cabo el experimento con Tommy John, lanzador en el equipo de béisbol de los Dodgers. Jobe extrajo un tendón del brazo derecho de John y lo usó para sustituir uno roto en el brazo izquierdo. Lo sostuvo sobre agujeros que abrió en el hueso arriba y debajo del codo. El jugador no solo pudo volver a jugar al béisbol, sino que lo hizo para ganar 170 juegos más en su carrera. Es decir, que su rendimiento mejoró notablemente tras la operación», en J. PÉREZ TRIVIÑO, «Deportistas tecnológicamente modificados y los desafíos al deporte», cit., p. 15.
} 
Por lo anterior, actualmente es difícil fijar un límite entre lo permitido -y aceptado- socialmente, y lo que no es, pues siguiendo a PÉREZ TrIVIÑo, así como deportistas han ingerido hormonas del crecimiento o se han operado la vista por problemas de miopía para mejorar su estado de salud, el asociar un ciborg-atleta con alguien que lleve implantes mecánicos, electrónicos, robóticos o tecnológicos en su cuerpo, no debiese ser tan absolutamente prohibido porque también son mejoras de la salud o de la calidad de vida de las personas ${ }^{30}$.

¿Cuál es el límite entonces? Siguiendo al mismo autor, postura que se considera acertada, y con bastante lógica, si las intervenciones son de carácter trans-humano, esto es, con un carácter mejorador de la igualdad de condiciones permitidos en un deporte, deberían crearse competiciones especiales y adaptaciones que premien otras virtudes que las actuales ${ }^{31}$. Sólo de esta manera podrá mantenerse la igualdad de condiciones entre quienes practiquen uno y otro deporte, según sus limitaciones y capacidades, conservándose además los postulados olímpicos de los que se habló al comienzo de este texto. Así por ejemplo, el periódico deportivo "Marca", publicó un reportaje confirmando que ya existen competiciones como la "Cybathlón de Zúrich", realizada en el Swiss Arena de Kotlen, en Zúrich (en octubre de 2016) con la presencia de humanos biónicos de 24 nacionalidades compuestos por deportistas discapacitados: el objetivo primordial era que tuviesen el control cibernético (persona-máquina) de sus sistemas ${ }^{32}$.

Finalmente, y conforme recomiendan QUIGLEY y AYIHONGBE, una regulación normativa correcta será aquella que sepa enfrentar la realidad de los ciborgs y sus tecnologías, hecho esto, podremos entender mejor los desafíos legales, y más

\footnotetext{
${ }^{30}$ J. PÉREZ TRIVIÑO, «Implantes y prótesis: de la terapia al ciborgdeportista», cit., p. 45.

${ }^{31}$ Concluye PÉREZ TRIVIÑO, «no obstante, la solución no consiste necesariamente en prohibir tales modificaciones sino que quizá sería razonable que para esos eventuales ciborgdeportistas transhumanos se establecieran competiciones separadas en las que eventualmente se pueda premiar a los deportistas por sus marcas, pero también los laboratorios o empresas que desarrollaran los implantes mejoradores, de igual forma a como se hace en el automovilismo o motociclismo», en J. PÉREZ TRIVIÑo, «Implantes y prótesis: de la terapia al ciborgdeportista», cit., p. 48.

${ }^{32}$ Y señala el reportaje que, "ya en la actualidad hay personas discapacitadas que disfrutan de tecnologías de asistencia más allá de las simples prótesis corporales para sustituir miembros u órganos dañados. Son los llamados implantes biónicos, cuya característica principal es que cuerpo y máquina trabajen juntos. Es decir, las señales biológicas son interpretadas por los sistemas electrónicos que manejan el implante, permitiendo que el sujeto lo controle mediante sus impulsos musculares o cerebrales", en «Llegan los deportistas cibernéticos. Olimpiadas para cyborgs», Noticia publicada en el periódico Marca (11.X.2016). Accesible en la web: http://www.marca.com/primera-plana/2016/10/11/57fbfe2946163-f94798b45f3.html
} 
importante aún, permitirá crear normas alternativas para tratar con mayor claridad esta realidad que avanza a pasos agigantados ${ }^{33}$.

\section{CONCLUSIONES}

En un mundo globalizado como el que actualmente vivimos existen múltiples factores que influyen en el comportamiento social y, en el caso de quienes se mueven en el mundo del deporte, significan un mejor o peor desarrollo de disciplinas conforme a su contexto cultural, lo cual se traduce también en una mayor o menor inversión económica para realizar diversos espectáculos de cara al público.

Son numerosos los eventos deportivos que se realizan diariamente a nivel mundial mejorando las oportunidades comerciales y expectativas de distintos agentes económicos e involucrados en el negocio del deporte. Por ello, es importante la tecnología que se utiliza cada día con mejores avances que sirven para llamar la atención de nuevos atletas y espectadores. El perjuicio y decepción se produce cuando esa tecnología se utiliza para obtener ventajas alterando los valores y la ética deportiva, como sucede con el fraude tecnológico en el ciclismo o en el ajedrez.

En el pasado hubo enfermedades que no tenían una cura definida, pero con el transcurso del tiempo los avances médicos y científicos están logrando mejorar cada vez más la vida de las personas que sufren de alguna dolencia, o, incluso mediante la manipulación de células, se ha logrado encontrar la solución a distintas dolencias incluso mortales. Así también, la tecnología ha logrado realizar implantes de prótesis o materiales biodegradables incorporados en seres humanos que sirven para darles un mejor bienestar.

Los implantes mecánicos, electrónicos, robóticos o tecnológicos también han sido utilizados por personas que quieren practicar deporte. Sin embargo, los dilemas

\footnotetext{
${ }^{33}$ Quigley, Muireann / AYIHONGBE, Semande, «Everyday cyborgs: on integrated persons and integrated goods», cit., pp. 28-32.
} 
éticos se encuentran cuando realmente son necesarios para mejorar la salud o si sólo son utilizados para obtener ventajas competitivas y que en relación a otros deportistas, sirven para mejorar el rendimiento del ser humano dejando de lado la terapéutica. Los ciborg-atletas son una realidad que poco a poco se han ido ganando un espacio en varios deportes, pero debido a los cuestionamientos sociales, se requiere de normas jurídicas específicas que sirvan para regular esta materia, tanto a nivel de salud y deportiva.

Son cada vez más los deportistas que se atreven a formar parte de un espectáculo en que utilizando implementos o sistemas cada vez más avanzados, provocan que en algunos casos exista una evidente desigualdad de condiciones, pero que al parecer se aceptan esos riesgos en aras de obtener competiciones en que se sobrepasen los límites del ser humano, aunque sea por una medalla y la gloria. La cuestión está en encontrar un punto medio que permita seguir disfrutando del deporte en igualdad de condiciones para todos.

\section{BIBLIOGRAFÍA}

- AtiEnZA MACÍAS, Elena, «Implicaciones ético-jurídicas de las intervenciones de mejora en el ámbito deportivo. Especial consideración del llamado 'dopaje genético'», en Carlos M. Romeo Casabona (dir.), Revista de Derecho y Genoma Humano. Cátedra Interuniversitaria Diputación Foral de Bizkaia de Derecho y Genoma Humano, U. de Deusto y U. del País Vasco UPV/EHU, Bilbao, 2014.

- GARCÍA CABA, Miguel «La publificación del régimen sancionador aplicable al control económico del fútbol profesional: una visión sucinta de la reciente doctrina del Tribunal Administrativo del Deporte en la materia», en A. Millán Garrido (dir.), Cuestiones actuales de derecho del deporte, editorial Reus, Madrid, 2015.

- Guerrero Olea, A. / Barba SÁnchez, R., «El modelo privado del Deporte en Europa: el deporte organizado convencionalmente», en A. PALOMAR OLMEDA (coord.), El modelo europeo del Deporte, editorial Bosch S.A., Barcelona, 2002. 
- PÉREZ TRIVIÑO, José Luis, «Implantes y prótesis: de la terapia al ciborgdeportista», en A. Millán Garrido / L. Cervantes liñán (dirs.), Anuario Iberoamericano de Derecho Deportivo, edit. Universidad Inca Garcilaso de la Vega, núm. 3, Lima, 2015.

- PÉREZ TRIVIÑo, José Luis, «Deportistas tecnológicamente modificados y los desafíos al deporte», en Revista de Bioética y Derecho, núm. 24, Universidad de Barcelona, Barcelona, enero 2012.

- Quigley, Muireann / AYiHOngBe, Semande, «Everyday cyborgs: on integrated persons and integrated goods», in Medical Law Review, Oxford University Press, 22.II.2018, pp. 1-33.

- REAL FERRER, Gabriel, «Dopaje: el debate que viene», en G. REAL FERRER (dir.), Justicia Deportiva, Editorial Aranzadi S.A., Pamplona, 1999.

- Ríos CoRbacho, José Manuel, Violencia, deporte y Derecho penal, Editorial Reus S.A., Madrid, 2014.

- Roxin, Claus, «Derecho penal y doping», en L. MoRILlas Cueva (dir.), Cuadernos de Política Criminal I, $2^{a}$ época, núm. 97, Editorial Centro de Estudios Superiores de Especialidades Jurídicas, Madrid, 2009.

- Verdugo Guzmán, Silvia, Código Mundial Antidopaje (trad. al español de S. Verdugo G.), Editorial Flores, México D.F., 2016.

- VeRdugo GuZMÁN, Silvia, «Imputación objetiva y riesgo permitido en intervenciones genéticas. El dopaje genético», en I. Jiménez Soto (dir.), Los Retos del deporte profesional y profesionalizado en la sociedad actual, editorial Reus, Madrid, 2016. 
- Verdugo GuZmán, Silvia, «Derecho y deporte profesional: globalización y ciborgdeportistas», en Revista Actualidad Penal, Editorial Instituto Pacífico, núm. 42, Lima, 2017.

\section{DOCUMENTOS}

- Directiva 90/385/ECC, de 20.VI.1990, relativa a la aproximación de las legislaciones de los Estados miembros sobre los productos sanitarios implantables activos.

- Libro Blanco sobre el Deporte, Comisión de las Comunidades Europeas, Bruselas, 11.VII.2007.

- Modelo de Deporte Europeo, Documento de consulta de la DG X (1999/C 374/14), Comisión Europea, Bruselas, 15.IX.1999.

- Olympic Charter, International Olympic Committee, Lausanne / Switzerland, 15.IX.2017. 